\section{THE BRITISH ENCYCLOPAEDIA OF MEDICAL PRACTICE}

Vols. $I I$ and $I 2$ and Index

Edited by The RT. Hon. LORD Horder, G.C.V.O., M.D., F.R.C.P. London: Butterworth \& Co., Ltd. 2nd Edition. Vol. II, pp. xv +753 , with 143 illustrations. 1952. 65s. Vol. 12, pp. xvi +777 , with 144 illustrations. 1952. 6os. Index, pp. 386. 1953. 65s.

The final two volumes of this remarkable work contain the names of nearly 40 new contributors. The general arrangement and most of the chapter headings are the same as in the first edition, but there are some important alterations. The section on skin diseases has been increased from 7 to 17 chapters, thus lengthening the section but gathering under one head in a single volume information that was previously widely scattered. The sections by Sir John McNee and Dr. Cullinan on spleen and liver diseases are amongst the best in these two volumes, and their completeness is indicated by the inclusion of a concise and helpful chapter on needle biopsy of the liver by Dr. Richard Terry.

A new chapter on poisons legislation by Dr. F. E. Camps is a reminder not only of the spate of new drugs that have appeared in recent years but also of the radical changes that the past decade has witnessed in the law relating to the sale of patent medicines as well as of dangerous drugs. The importance of metallurgy in medicine is stressed by Mr. Leon Gillis's useful new chapter on Vitallium and other metals used in surgery. Approximately eight chapters on subjects such as visceroptosis, Simmond's disease, silicosis and tremor have been omitted from the present volumes; most have been included appropriately elsewhere. Visceroptosis, however, no longer appears in the Index-doubtless being regarded by the Editor as one of the ragbags of clinical medicine.

As in the earlier volumes of the present work, the reviewer has been impressed not only by the overall excellence of the contributions themselves and of their arrangement, but also by the high standard of production and by the compactness and format of the volumes. The many beautiful coloured plates which grace the pages of the new work, theo fine quality paper and the clear and faultless printing? deserve the highest praise.

Editors, contributors and publishers are to bees congratulated for piloting through its many and complex stages this vast and important work. Now旡 that the Index, which appears to be both accurates and comprehensive, is completed, they may rest a brief space from their great task, which has given to the medical profession in this country and abrogde what must surely be one of the most authoritatiogec and best produced works of its kind in existence.

D.S.L.

\section{A POCKET OBSTETRICS}

By A. H. C. Bell, F.R.C.S. Third edition. Pp. viii +156 , with 14 illustrations. London: J. \& A. Churchill, Ltd. r 953. 8s. 6d.

Within the self-imposed limitations implied in the title, this new edition is excellent. The contents are irreproachable, present a common-sense approach to obstetrics, and are reasonably representative of orthodox London teaching. The maino defects arise from the need to compress to pocket edition size.

\section{AIDS TO GYNAECOLOGY}

By W. R. Winterton, M.A., M.B., B.Ch.N్ Eleventh edition. Pp. viii + 196 , with $I_{5}$ illustrations. London: Baillière, Tindall \& Cox. I 953 . $6 \mathrm{~s}$.

This edition is a distinct improvement over its predecessor. In the main it does what it sets out ${ }_{+}^{+}$ to do, that is, act as an aid to a standard textbook. 